\title{
DRESS induced by amoxicillin-clavulanate in two pediatric patients confirmed by lymphocyte toxicity assay
}

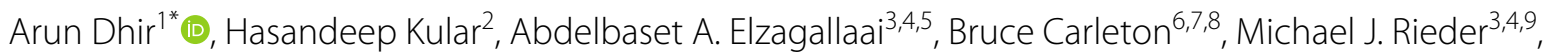
Raymond Mak ${ }^{2}$ and Tiffany Wong ${ }^{10}$

\begin{abstract}
Background: Drug reaction with eosinophilia and systemic symptoms (DRESS) is a rare but serious delayed hypersensitivity reaction that can be caused by antibiotic exposure. The reaction typically develops in 2 to 6 weeks. The pathophysiology is thought to involve toxic drug metabolites acting as a hapten, triggering a systemic response. The diagnosis is made clinically but can be confirmed using assays such as the lymphocyte toxicity assay (LTA), which correlates cell death upon exposure to drug metabolites with susceptibility to hypersensitivity reactions.
\end{abstract}

Case presentations: Case 1 involves a previously healthy 11-month-old male with first exposure to amoxicillinclavulanate, prescribed for seven days to treat a respiratory infection. The patient developed DRESS fourteen days after starting the drug and was successfully treated with corticosteroids. LTA testing confirmed patient susceptibility to hypersensitivity reactions with amoxicillin-clavulanate. Parental samples were also tested, showing both maternal and paternal susceptibility. Neither parent reported prior hypersensitivity reactions. Lifelong penicillin avoidance for the patient was advised along with the notation in medical records of penicillin allergy. The parents were advised to avoid penicillin class antibiotics and be monitored closely for DRESS if they are exposed.

Case 2 involves an 11-year-old female with atopic dermatitis with first exposure to amoxicillin-clavulanate, prescribed for ten days to treat a secondary bacterial skin infection. She developed DRESS eleven days after starting antibiotics and was successfully treated with corticosteroids. LTA testing confirmed patient susceptibility to hypersensitivity reactions with amoxicillin-clavulanate. Maternal samples were also tested and showed sensitivity. The mother reported no prior hypersensitivity reactions. Lifelong penicillin avoidance for the patient was advised along with the notation in medical records of penicillin allergy.

Conclusions: Amoxicillin-clavulanate is a commonly used antibiotic and the cases we have described suggest that it should be recognized as a potential cause of DRESS in pediatric patients. Furthermore, these cases contribute to current literature supporting that there may be a shorter latent period in DRESS induced by antibiotics. We have also shown that the LTA can be a helpful tool to confirm DRESS reactions, and that testing may have potential implications for family members.

Keywords: "Drug reaction with eosinophilia and systemic symptoms", DRESS, Lymphocyte Toxicity Assay, Antibiotics, Amoxicillin-clavulanate

\footnotetext{
*Correspondence: arun.dhir@alumni.ubc.ca

1 Department of Medicine, University of British Columbia, Vancouver, BC, Canada
}

Full list of author information is available at the end of the article

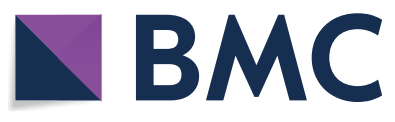

(c) The Author(s) 2021. This article is licensed under a Creative Commons Attribution 4.0 International License, which permits use, sharing, adaptation, distribution and reproduction in any medium or format, as long as you give appropriate credit to the original author(s) and the source, provide a link to the Creative Commons licence, and indicate if changes were made. The images or other third party material in this article are included in the article's Creative Commons licence, unless indicated otherwise in a credit line to the material. If material is not included in the article's Creative Commons licence and your intended use is not permitted by statutory regulation or exceeds the permitted use, you will need to obtain permission directly from the copyright holder. To view a copy of this licence, visit http://creativeco mmons.org/licenses/by/4.0/. The Creative Commons Public Domain Dedication waiver (http://creativecommons.org/publicdomain/ zero/1.0/) applies to the data made available in this article, unless otherwise stated in a credit line to the data. 


\section{Background}

Drug reaction with eosinophilia and systemic symptoms (DRESS) is a rare but potentially fatal delayed hypersensitivity reaction. It is hypothesized that the reaction involves a combination of the activation of drug-specific T-lymphocytes, latent viral reactivation, accumulation of reactive drug metabolites, as well as genetic predisposition [1]. The toxic metabolite acts as a hapten, initiating an immune response. DRESS is classically associated with anticonvulsant agents, but $15-37 \%$ of DRESS cases may be due to antibiotics, [2] with one with study reporting up to $74 \%$ (39\% to vancomycin, $23 \%$ to beta-lactams) [3]. The reaction typically has a latency period of 2 to 6 weeks $[2,4]$. Symptoms include fever, diffuse rash, lymphadenopathy, hematologic abnormalities (eosinophilia, atypical lymphocytosis), and ultimately internal organ involvement [2]. This diagnosis is made clinically, often supported by tools such as the European Registry of Severe Cutaneous Adverse Reaction (RegiSCAR) validation scoring criteria [5].

Additional tools that may be used to confirm a diagnosis of DRESS include patch testing and in-vitro assays. The lymphocyte toxicity assay (LTA) is one such assay based upon based upon the premise that DRESS may be triggered by accumulation of toxic metabolites [6]. The patient's lymphocytes, isolated from peripheral blood samples and acting as a surrogate for target tissue cells, are incubated with the suspected drug in presence of phenobarbital-induced mammalian hepatic microsomes as a source of cytochrome $\mathrm{P} 450$ monooxygenase activity. The degrees of cell death in samples isolated from patients and from healthy volunteers are then quantified and compared. Enhancement of cell death is hypothesized to correlate with the patient's susceptibility to developing hypersensitivity reactions to the agent being tested.

Here, we present two cases of pediatric patients with DRESS induced by amoxicillin-clavulanate and the results of their LTA testing.

\section{Case presentations}

Case 1 involves a previously healthy 11-month-old male with first exposure to amoxicillin-clavulanate, prescribed for seven days to treat a respiratory infection. Fourteen days after starting antibiotics, he presented with fevers, lethargy, and a widespread generalized erythematous maculopapular rash. Laboratory investigations showed reactive lymphocytes, peripheral eosinophilia, and hepatitis. Testing for ANA, hepatitis A and B, EBV, CMV, HHV6, mycoplasma, chlamydia, and blood cultures were negative. A RegiSCAR Diagnosis Score of 6 confirmed definite DRESS (Table 1). The patient received systemic steroids, resulting in normalization of lab work and improvement of symptoms. LTA testing showed a concentration-dependent decline in viability in

Table 1 RegiSCAR Scoring System for Classifying DRESS Cases, adapted from Cho et al. [5] applied to patients described in Case 1 and Case 2

\begin{tabular}{|c|c|c|c|c|c|c|}
\hline \multirow[t]{2}{*}{ Items } & \multicolumn{3}{|c|}{ Score } & \multirow[t]{2}{*}{ Comments } & \multirow[t]{2}{*}{ Case 1 score } & \multirow[t]{2}{*}{ Case 2 score } \\
\hline & -1 & 0 & 1 & & & \\
\hline Fever $\geqq 38.5^{\circ} \mathrm{C}$ & $\mathrm{N} / \mathrm{U}$ & Y & & & 0 & 0 \\
\hline Enlarged lymph nodes & & $N / U$ & Y & $>1 \mathrm{~cm}$ and $\geqq 2$ different areas & 0 & 0 \\
\hline $\begin{array}{c}\text { Eosinophilia } \geqq 0.7 \times 10^{9} / \mathrm{L} \text { or } \geqq \\
10 \% \text { if } W B C<4.0 \times 10^{9} / \mathrm{L}\end{array}$ & & N/U & Y & Score 2 , when $\geqq 1.5 \times 10^{9} / \mathrm{L}$ or $\geqq 20 \%$ if WBC $<4.0 \times 10^{9} / \mathrm{L}$ & 1 & 1 \\
\hline Atypical lymphocytosis & & $N / U$ & Y & & 1 & 0 \\
\hline Skin rash & & & & Rash suggesting DRESS: $\geqq 2$ symptoms: purpuric lesions & & \\
\hline Extent $>50 \%$ of BSA & & $N / U$ & Y & (other than legs), infiltration, facial edema, psoriasiform & 1 & 1 \\
\hline Rash suggesting DRESS & N & U & Y & & 1 & 1 \\
\hline Skin biopsy suggesting DRESS & N & Y/U & & & 0 & 0 \\
\hline Organ involvement & & $\mathrm{N}$ & Y & Score 1 for each organ involvement, maximal score: 2 & 1 & 1 \\
\hline Rash resolution $\geqq 15$ days & $N / U$ & Y & & & 0 & 0 \\
\hline Excluding other causes & & $\mathrm{N} / \mathrm{U}$ & Y & $\begin{array}{l}\text { Score } 1 \text { if } 3 \text { tests of the following tests were performed } \\
\text { and all were negative: HAV, HBV, HCV, Mycoplasma, } \\
\text { Chlamydia, ANA, blood culture }\end{array}$ & 1 & 1 \\
\hline Total score & & & & & 6 & 5 \\
\hline
\end{tabular}

The diagnosis of DRESS syndrome is then made based on the total score: $<2$ points: no case; $2-3$ points: possible case; $4-5$ points: probable case; $>5$ points: definite case

ANA: anti-nuclear antibody; BSA: body surface area; HAV: hepatitis A virus; HBV: hepatitis B virus; HCV: hepatitis C virus; N: no; U: unknown; WBC: white blood cell; Y: yes 
the patient's white blood cells compared to controls after incubation with penicillin and its metabolites (Fig. 1). Lifelong penicillin avoidance was advised along with the notation in medical records of penicillin allergy. Parental samples were tested, showing a concentration-dependent decline in cell viability when exposed to penicillin and its metabolites. Neither parent reported prior adverse reactions to antibiotics. They were counselled that the implications of a positive LTA without a prior reaction are unknown. They were also advised that alternatives to penicillin class antibiotics should be used to treat infections, and that if exposed to such antibiotics, they should be monitored closely for symptoms of DRESS.

Case 2 involves an 11-year-old female with atopic dermatitis with a first exposure to amoxicillinclavulanate, prescribed for ten days to treat a secondary bacterial skin infection. She developed fevers and decreased appetite eleven days after starting antibiotics. This progressed to diffuse erythrodermic, maculopapular eruption, superficial desquamation, facial angioedema, peripheral eosinophilia, hepatitis, and lymphadenopathy. The patient's ANA and blood cultures were negative. Her RegiSCAR-Group Diagnosis Score was 5, suggesting probable DRESS (Table 1). LTA testing showed a substantial decline in viability of the patient's white blood cells compared to controls when exposed to penicillin and its metabolites (Fig. 2). The patient received systemic corticosteroids, resulting in normalization of lab work and improvement of symptoms. Lifelong penicillin avoidance was advised along with the notation in medical records of penicillin allergy. Maternal samples also showed concentration-dependent decreased cell viability. The patient's mother had no prior adverse reactions to antibiotics.

Case 1 lymphocyte toxicity assay results show a concentration-dependent decline in patient and parent lymphocyte viability when incubated with penicillin and activated mammalian-derived microsomes. Compared to control cells, the patient and parent cells demonstrated decreased viability when incubated with penicillin, and showed further decline when incubated with penicillin metabolites generated by the activated microsomes.

Case 2 lymphocyte toxicity assay results show a concentration-dependent decline in patient and parent lymphocyte viability when incubated with penicillin and activated microsomes. Compared to control cells, the patient and parent cells demonstrated decreased viability when incubated with penicillin, and showed further decline when incubated with penicillin metabolites generated by the activated microsomes.

\section{Discussion}

Few cases of DRESS associated with amoxicillinclavulanate have been published, particularly in children. One case report described a 12-year-old male who received empiric amoxicillin-clavulanate for a fever and cough and subsequently developed DRESS within a ten day period [7]. Similarly, our patients developed symptoms within two weeks as opposed to the typically reported 2 to 6 week period, supporting the possibility of a shorter latency period for DRESS induced by antibiotics in children $[2,4]$.

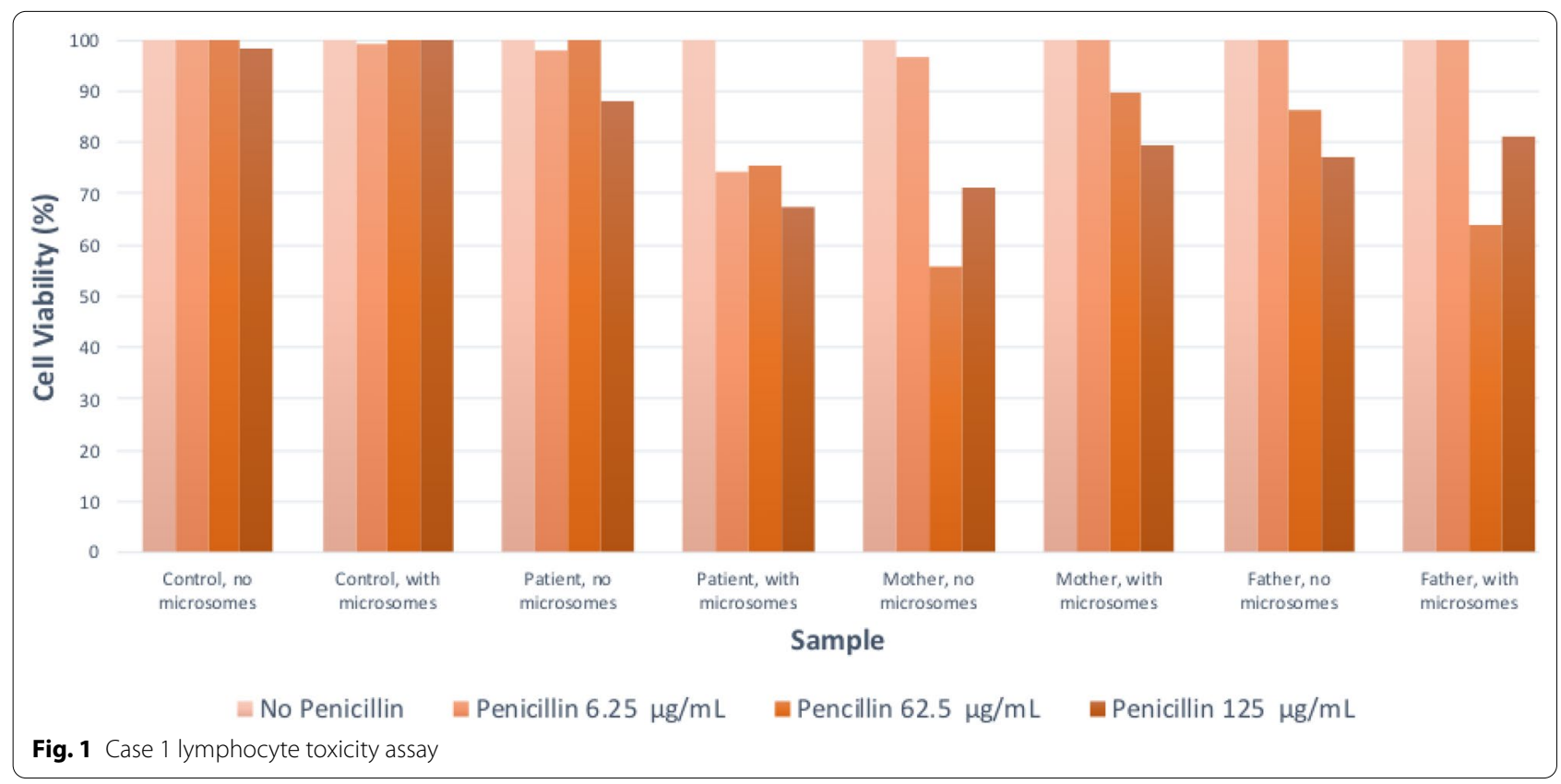




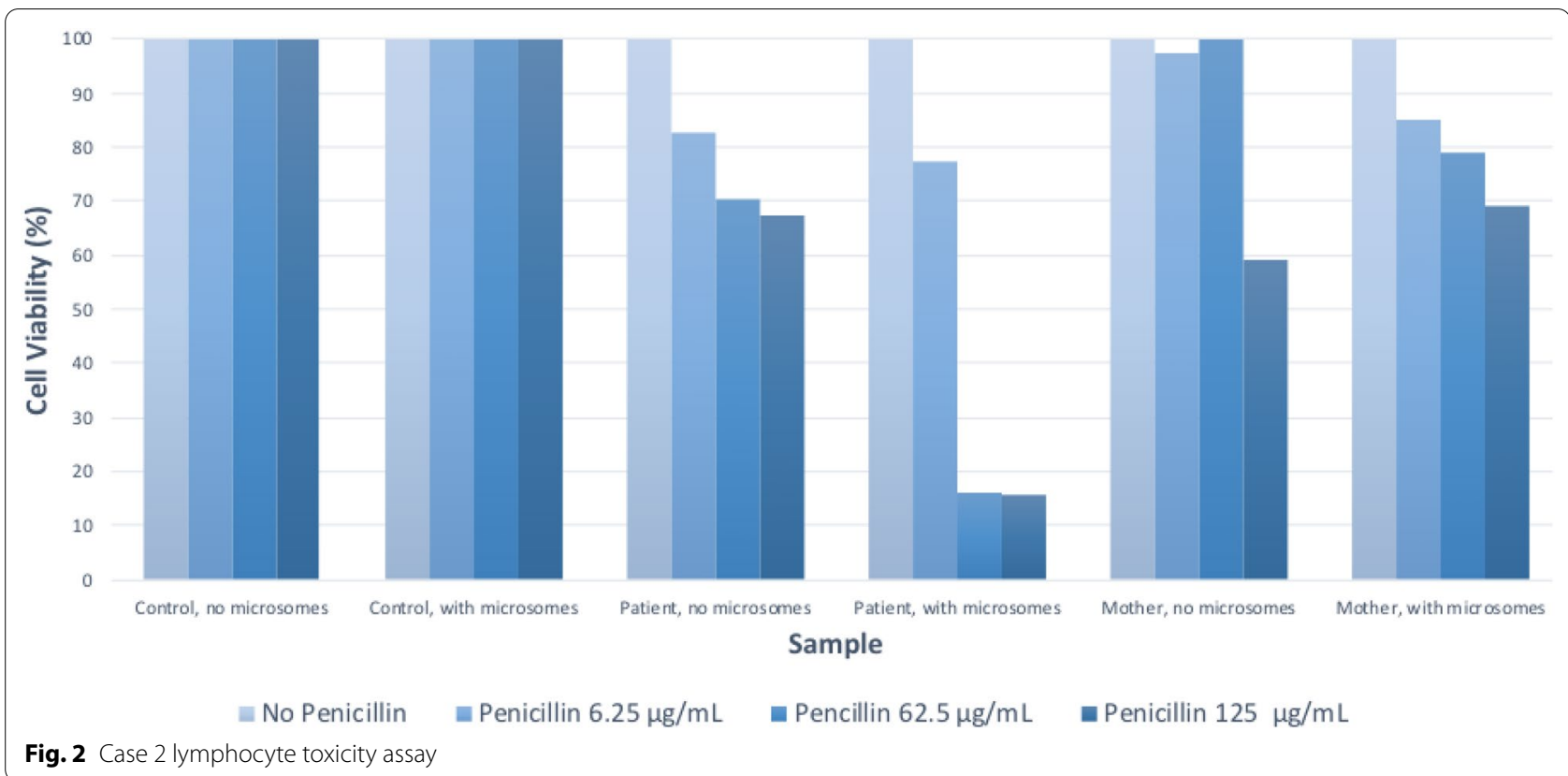

Research on the sensitivity and specificity of the LTA is limited, partly due to the test being limited to wellequipped research centers and validated only for few classes of drugs. In their retrospective study, Elzagallaii et al. found that amongst 13 patients with re-exposure events to beta-lactam antibiotics, the LTA showed a sensitivity of $40 \%$ and a specificity of $100 \%$ [8]. The cases we have described further suggest that the LTA may be a useful tool in the evaluation of DRESS reactions.

The use of LTA to risk stratify relatives of patients who have had DRESS has not been previously reported. With regards to Case 1, both parents had abnormal LTA results, suggesting a genetic contribution to the patient's sensitivity. An association between human leukocyte antigen haplotypes and susceptibility to DRESS is well established for allopurinol, carbamazepine, abacavir and other medications, [2] although no such strong association has yet been discovered with penicillinclass antibiotics. The LTA test supports the hapten hypothesis, i.e. that reactive metabolites contribute to the development of DRESS via hapten formation and assessment of white blood cell toxicity can serve to identify phenotypic vulnerability in patient cells [8].

\section{Conclusions}

Amoxicillin-clavulanate is a commonly used antibiotic and the cases we have described suggest that it should be recognized as a potential cause of DRESS in pediatric patients. Furthermore, these cases contribute current literature supporting that there may be a shorter latent period in DRESS induced by antibiotics. We have also shown that the LTA can be a helpful tool to confirm DRESS reactions, and that testing may have potential implications for family members.

\section{Abbreviations}

DRESS: Drug reaction with eosinophilia and systemic symptoms; LTA: Lymphocyte toxicity assay.

\section{Acknowledgements}

None

\section{Authors' contributions}

HK, TW, and RM were directly involved in patient care and/or had knowledge of the patients' cases. AD performed a literature review and major contributor in writing the manuscript. BC and MR facilitated the use of the lymphocyte toxicity assay. The work of AE was cited in the manuscript and he provided feedback on our work. All authors read and approved the final manuscript.

\section{Funding}

No funding was required for this study. The lymphocyte toxicity assay was performed at the University of Western Ontario on a research basis.

\section{Availability of data and materials}

The datasets used and analysed during the current study are available from the corresponding author on reasonable request.

\section{Declarations}

Ethics approval and consent to participate Not applicable.

\section{Consent for publication}

Consent for publication was obtained from the parents of both patients.

\section{Competing interests}

The authors declare that they have no competing interests. 


\section{Author details}

1 Department of Medicine, University of British Columbia, Vancouver, BC, Canada. ${ }^{2}$ Division of Allergy and Immunology, Department of Medicine, University of British Columbia, Vancouver, BC, Canada. ${ }^{3}$ Department of Physiology and Pharmacology, Western University, London, ON, Canada. ${ }^{4}$ Department of Pediatrics, Western University, London, ON, Canada. ${ }^{5}$ Robarts Research Institute, Western University, London, ON, Canada. ${ }^{6}$ Division of Translational Therapeutics, Department of Pediatrics, University of British Columbia, Vancouver, BC, Canada. ${ }^{7}$ British Columbia Children's Hospital Research Institute, University of British Columbia, Vancouver, BC, Canada. ${ }^{8}$ Pharmaceutical Outcomes Program, British Columbia Children's Hospital, Vancouver, BC, Canada. ${ }^{9}$ CIHR-GSK Chair in Paediatric Clinical Pharmacology, Children's Hospital of Western Ontario, London, ON, Canada. ${ }^{10}$ Division of Allergy and Immunology, Department of Pediatrics, University of British Columbia, Vancouver, BC, Canada.

Received: 22 December 2020 Accepted: 11 March 2021

Published online: 05 April 2021

\section{References}

1. Husain Z, Reddy BY, Schwartz RA. DRESS syndrome: part I clinical perspectives. J Am Acad Dermatol. 2013;68(5):693.e1-693.e14.

2. Blumenthal KG, Patil SU, Long AA. The importance of vancomycin in drug rash with eosinophilia and systemic symptoms (DRESS) syndrome. Allergy Asthma Proc. 2012;33(2):165-71.
3. Wolfson AR, Zhou L, LiY, Phadke NA, Chow OA, Blumenthal KG. Drug Reaction with eosinophilia and systemic symptoms (dress) syndrome identified in the electronic health record Allergy Module. J Allergy Clin Immunol Pract. 2019;7(2):633-40.

4. Sasidharanpillai S, Sabitha S, Riyaz N, Binitha MP, Muhammed K, Riyaz A, et al. Drug reaction with Eosinophilia and systemic symptoms in children: a prospective study. Pediatr Dermatol. 2016;33(2):e162-5.

5. Cho Y-T, Yang C-W, Chu C-Y. Drug reaction with eosinophilia and systemic symptoms (DRESS): an interplay among drugs, viruses, and immune system. Int J Mol Sci. 2017;18(6):1243.

6. Kearns GL, Wheeler JG, Rieder MJ, Reid J. Serum sickness-like reaction to cefaclor: lack of in vitro cross-reactivity with loracarbef. Clin Pharmacol Ther. 1998;63(6):686-93.

7. Chua GT, Rosa Duque JS, Chong PCY, Lee PPW, Lau YL, Ho MHK. Paediatric case series of drug reaction with eosinophilia and systemic symptoms (DRESS): 12-year experience at a single referral centre in Hong Kong and the first reported use of infliximab. Eur Ann Allergy Clin Immunol. 2018:50(6):273-6.

8. Elzagallaai AA, Jahedmotlagh Z, Del Pozzo-Magaña BR, Knowles SR, Prasad AN, Shear NH, et al. Predictive value of the lymphocyte toxicity assay in the diagnosis of drug hypersensitivity syndrome. Mol Diag Ther 2010;14(5):317-22.

\section{Publisher's Note}

Springer Nature remains neutral with regard to jurisdictional claims in published maps and institutional affiliations.
Ready to submit your research? Choose BMC and benefit from:

- fast, convenient online submission

- thorough peer review by experienced researchers in your field

- rapid publication on acceptance

- support for research data, including large and complex data types

- gold Open Access which fosters wider collaboration and increased citations

- maximum visibility for your research: over 100M website views per year

At BMC, research is always in progress.

Learn more biomedcentral.com/submissions 